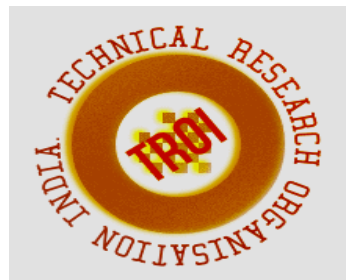

\title{
ENHANCEMENT OF POWER QUALITY IN WIND ENERGY SYSTEM AND IMPLEMENTATION OF SMART CURTAIN
}

\begin{abstract}
Prema. $V^{1}$, Amita ${ }^{2}$, Kruthishree.T.R ${ }^{3}$, Pallavi.C.S ${ }^{4}$
Sri Venkateshwara College of Engineering, Department of Electrical and Electronics Engineering , Bangalore , Karnataka , India

E-Mail: prema.smile09@gmail.com ${ }^{1}$

Abstract

The major contribution towards generation of electricity is done by using renewable energy sources like solar, wind, tidal and hybrid. Today due to shortage of fuels and environmental pollution caused by greenhouse gases, renewable energy has come to an effect. Large wind farms connected to power grid results in major power quality problems like current and voltage harmonics, voltage sag/swell, voltage unbalance etc are the major reasons which cause damage to the electrical equipment. Due to these reasons it causes poor power

important to maintain high standard power quality.

In this project custom power devices like PSTATCOM can be effectively utilized to improve the quality of power that is supplied to the customers. The continuity of supply is defined as the reliability. The problems in the distribution lines can be divided into two major categories. The first category is power quality and the second is power reliability. The problems in the first category of distribution lines consists of harmonic distortions, impulses and swells and second group consists of voltage sags and outages.
\end{abstract} quality and this may leads to cause serious impacts on electrical loads.Hence it finally results in huge economic losses. When WECS is connected to a grid the power quality problems such as voltage dip, voltage swell and harmonic contents are mitigated. This results show that the quality of power is increased with STATCOM. With the development in the smart home industry, smart curtain would be introduced into the life of people which is based on Arduino.

Keywords: Solar panel, Battery, Solar energy, Wind energy, STATCOM circuit, LDR Sensor, Microcontroller, Power quality.

\section{INTRODUCTION}

When wind turbine is integrated to grid it causes power quality problems which are generally complex and difficult to detect. Technically speaking, the ideal AC line supply by the utility system should be a pure sine wave of fundamental frequency $(50 / 60 \mathrm{~Hz})$. Hence poor power quality causes major problem like loss of production, it can even cause damage to equipment or appliances and can even be dangerous to human health. Therefore it is
Usually the power quality problems is concerned with the distribution side. It also has an impact on the quality of power that is supplied by the transmission line.

In this project we have also introduced the design of an intelligent control system of curtain and the reasonable solution for existing problems in the control system of curtain.

\section{CIRCUIT DIAGRAM}

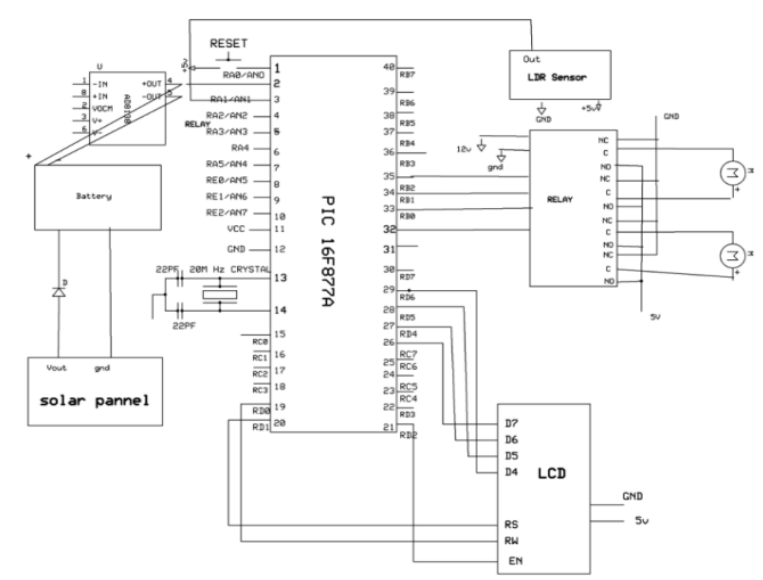

Fig.1 Circuit of PIC controller board 
In our project the PIC (16F877A) controller will act as brain of the controlling device in the set up. It is one of the most advanced microcontroller from Microchip which has two 8 bit and one 16 bit timer. One of the major advantage of PIC controller is that the data can be written or erased as many times as possible because it uses FLASH memory technology. It is a 40 pin microcontroller in which 33 pins are for input and output. It also consists of capture and compare modules , serial ports, parallel ports and five input/output ports. We use the $12 \mathrm{~V}$ dc adapter for giving power supply to the controller board.

\section{BLOCK DIAGRAM}

The block diagram of developed model of smart curtain and wind energy system for battery charging is shown in fig. 2

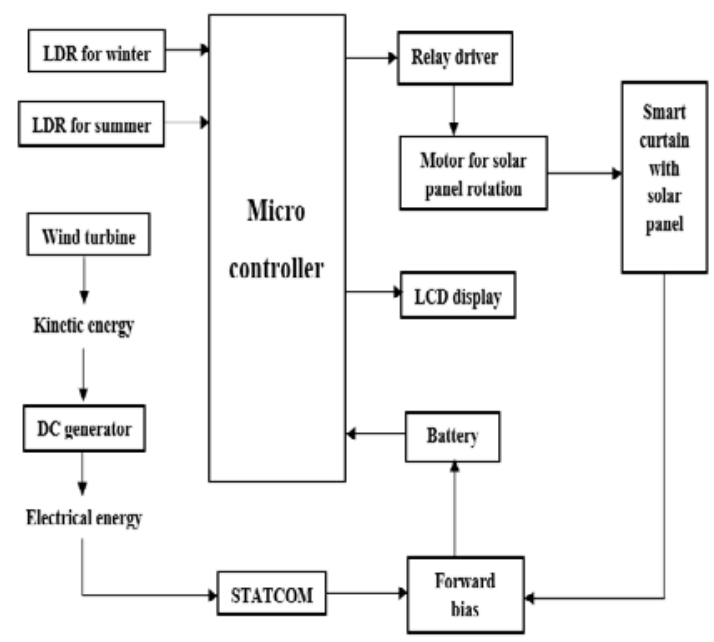

Fig.2 Block diagram of smart curtain and wind energy system

Block diagram consists of two sections namely,

1. Wind turbine

2. Smart curtain

\section{A. Wind turbine}

When the wind blows, wind turbine rotates and generates kinetic energy. The generated kinetic energy is applied to the DC generator which converts mechanical energy to electrical energy and it is given to the STATCOM. The STATCOM circuit is used to regulate the voltage by controlling the amount of reactive power injected at its terminal or which is absorbed from the wind turbine.Since there should be no reverse flow of stored energy forward bias circuit is used and the generated energy is stored in the battery. The amount of energy stored in the battery is displayed on the LCD display by using microcontroller.

\section{B. Smart curtain}

In this section LDR(Light Dependent Resistor) sensor is designed for winter and summer purpose. LDR is a component consisting of variable resistance that changes with the change in the light intensity and hence this property makes them useful in light sensing circuits. It works on the principle of photo conductivity. A Relay driver IC is an electro-magnetic switch that will be used whenever we want to use a low voltage circuit to switch a light bulb $\mathrm{ON}$ and OFF which is connected to $220 \mathrm{~V}$ mains supply.

\section{METHODOLOGY}

\section{Wind Energy}

Wind power is the conversion of wind energy into a useful type of energy, such as using wind turbines to develop electrical power, windmills use for mechanical power, wind pumps use for water pumping or drainage, or sails to propel ships. A wind farm is the place where a pair of wind turbines are located for the production of electricity. In a large wind farm have been contain several hundred individual wind turbines, and cover an enlarged area of hundreds of square miles, but the land between the turbines might be used for agricultural or other purposes. A wind farm is also located near offshore.

\section{Wind generating system}

The successfully operating wind generating turbines are also present all over the world. Into the operation of fixed-speed wind turbine, all fluctuations into the wind speed are transmitted as fluctuations into the mechanical torque, power on the grid side and accelerate large voltage fluctuations. The power quality problems such as voltage sag, swells, flickers, harmonics etc can be observed in wind generation, transmission and distribution network and the wind generator causes disturbances in distribution network. One among the simple way of running a wind generating system is to use the induction generator (IG) connected directly to the grid system.

\section{SYSTEM CONFIGURATION AND PRINCIPLE OF OPERATION}

The Static Synchronous Compensator works on the principle of current control voltage source 
inverter (VSI) which injects the current into the grid in the simplest way so that the supply current is free from harmonics and the phaseangle with respect to supply voltage has a desired value. The injected current from inverter can eliminate the reactive part and harmonic a part of the non-linear load and induction generator current, so it improves the power factor and therefore the power quality.

The energy is produced by the wind turbine and it is shown by the glowing LED. With the help of STATCOM we enhance the power produced. For example if the wind turbine produces around $3 \mathrm{v}$ of energy, with the help of STATCOM the voltage is enhanced to an approximately of $12 \mathrm{~V}$ that is shown with the help of a multimeter.

\section{Smart curtain}

Presents both a block diagram and a photograph of the control system, which includes several components: the sunlight illumination detection, outdoor environment detection and the microcomputer based on Controller. The microcontroller of this system was designed to detect the factors that influence the opening and closing state of curtain and provide the control signal to the actuator.

\section{FLOW CHART}

The flowchart of smart curtain and wind energy system is as shown in fig. 3

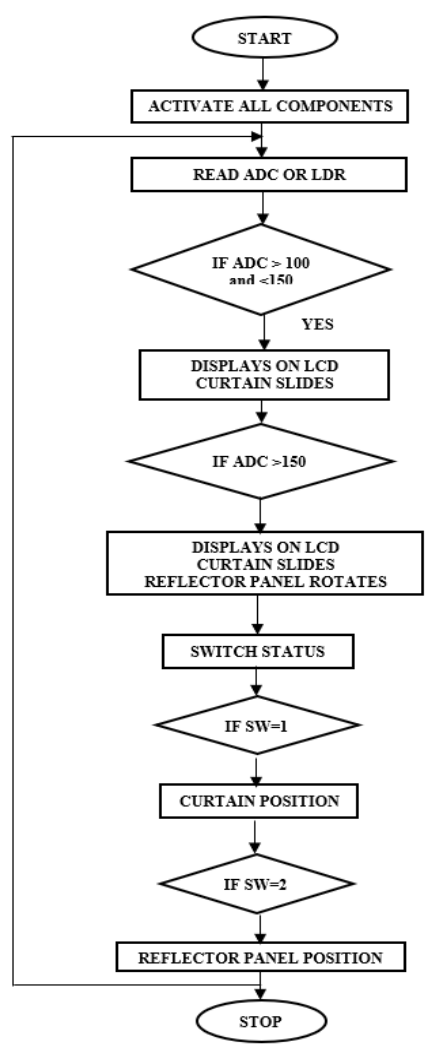

Fig.3 Flow chart of smart curtain and wind energy system

\section{HARDWARE RESULT}

This figure shows the whole experimental setup which includes the solar panels, controller board and the various hardware parameters of the hardware setup.

Step1: The energy is produced by the wind turbine and it is shown by the glowing LED. with the help of STATCOM we enhance the power produced. For example if the wind turbine produces around 3v of energy, with the help of STATCOM the voltage is enhanced to an approximately of $12 \mathrm{~V}$ that is shown with the help of a multimeter.

Step2: Here we use the solar energy as the input source for getting a quick result when solar panel is exposed to the solar radiation. The smart curtain system implemented has been designed for two conditions :

(i). when the light intensity is between 100 to 150 only the curtain operates and is designed for winter.

(ii). When the light intensity is above 150 ,both curtain and reflector operates and is designed for summer purpose to use maximum energy available.

Hence the panel gets heated up and the power collected from the panel will be stored in the battery.

The experimental setup of the project is shown in below fig. 4

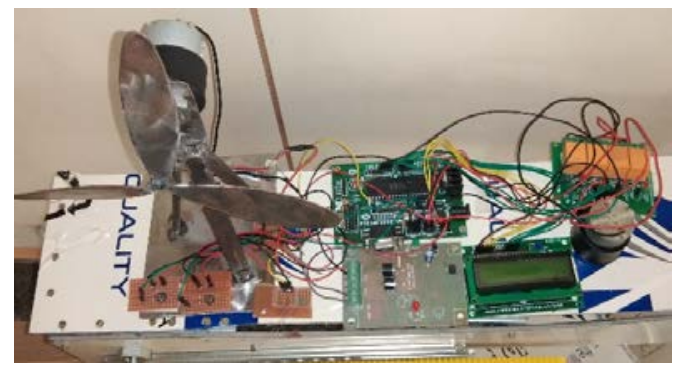




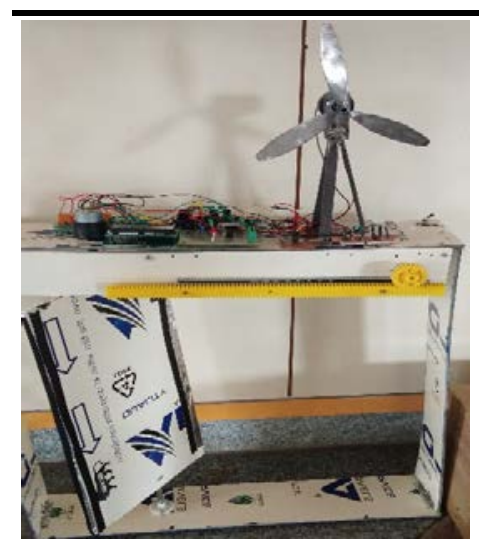

Fig.4 Hardware kit

\section{CONCLUSION}

In this study we are presenting the implementation of STATCOM-based control scheme for power quality enhancement in to the grid connected wind generating system with nonlinear load is done and the flicker parts of the load current is cancelled out by maintaining the source voltage and current in-phase.

By detecting and analyzing the factors that include the sunlight illumination, outdoor environmental conditions, the designed control system of curtains has the characteristics of high intelligence, compact, multifunctionalization, which are expected to have been widely used in high-grade office buildings, convention centres, hotels and other places.

The microcontroller of this system is designed to detect the factors that influence the opening and closing state of curtain and store the solar energy collected for two different seasons i.e. for winter and summer.

\section{REFERENCES}

[1]. Sanjiba Kumar Bisoyi, R.K.Jarial, R.A.Gupta, "Modeling and control of variable speed wind turbine equipped with PMSG", International Journal of Emerging Technologies in Computational and Applied Sciences (IJETCAS), pp. 56 - 62, Oct. 2013.

[2]. C. Kocatepe, A. Inan, O. Arikan et al., "Power quality assessment of grid-connected wind farms considering regulations in Turkey,”
Renewable andSustainable Energy Reviews, vol. 13, no. 9, pp. 2553 - 2561, June 2009.

[3]. Aswathy.B.Raj and P.C. Thomas, "An efficient PMSG based wind energy conversion system with power quality improvement features ," ACEEE Int. J. on Electrical and Power Engineering, vol. 03, no. 01, Feb 2012.

[4]. Sourav Ghosh, Pradip Kumar Saha, Gautam Kumar Panda, "Wind energy conversion system connected with grid using permanent magnet synchronous generator," International Journal of Advanced Research in Electrical, Electronics and Instrumentation Engineering, vol. 4, issue 1, pp.120 - 127, January 2015.

[5]. Mona Naguib Eskander and Sanaa Ibrahim Amer, "Mitigation of voltage dips and swells in grid connected wind energy conversion systems," IETE journal of research, vol. 57, issue 6, Nov - Dec. 2011.

[6]. Arindam Ghosh, "Power Quality Enhancement Using Custom Power Devices”, Kluwer Academic Publishers Boston / Dordrecht / London, 2002.

[7]. Abhijit A Dutta, Manisha Sabley, B.S.Sudame and A.N.Kadu ,"Harmonic compensation in power system using active power filters,” Int. Journal of Multidisciplinary and Current research, vol. 2, pp. 188 - 192, , Nov/Dec. 2013.

[8] Pramod Raikar, "Power Quality Enhancement of Grid Connected Wind Energy System Using Static Synchronous Compensator" Journal of Advanced Engineering Research, ISSN: 2393-8447 Vol.1, pp.77-85, Issue 1, 2014.

[9]. Yashaswini Patel A. B, T.R.Narasimhe Gowda, B.Kantharaj, Ramesh G.B, “ Simulation of wind farm using UPQC in weak grid connection”, International Journal of Electrical, Electronics and Computer Systems (IJEECS), vol -3, issue-5, pp.22 -26, 15/10/2015. 